\title{
Comparison of Ocular Biometry between Primary Open Angle Glaucoma Patients and Normal subjects
}

\author{
Nisha Manandhar ${ }^{\mathbb{D} \otimes}$, Chandni Pradhan $^{2}$, Purushottam Joshi $^{3}$, Prabha Subedi $^{3}$, Pranav Shrestha $^{3}$ \\ ${ }^{1}$ Kirtipur Eye Hospital, Kirtipur, Kathmandu, Nepal \\ ${ }^{2}$ Birtamode Eye Hospital, Birtamode, Jhapa, Nepal \\ ${ }^{3}$ Mechi Eye Hospital, Birtamode, Jhapa, Nepal
}

\begin{abstract}
Introduction: Glaucoma is one of the major causes of irreversible blindness. In Nepal, the most common type of Glaucoma seen is Primary Open Angle Glaucoma. There are many risk factors associated with Primary Open Angle Glaucoma. The main objective of the study was to compare ocular biometric parameters in patients diagnosed with Primary Open Angle Glaucoma and age matched controls.
\end{abstract}

Material and methods: This is a hospital based cross sectional study done at Mechi Eye Hospital. The study included 137 cases of Primary Open Angle Glaucoma and 75 normal individuals as control. Axial length (AL), anterior chamber depth (ACD), Keratometry ' $\mathrm{K}$ ' value and Central Corneal Thickness (CCT) were measured. Mann - Whitney U test was used for statistical analysis.

Results: Mean age in Primary Open Angle Glaucoma group was (55.25 \pm 10.16 years) and in the control group was (60.96 \pm 10.91 years). Axial length in the Primary Open Angle Glaucoma group (23.16 \pm 1.19 $\mathrm{mm})$ was deeper as compared to the control group $(22.69 \pm 0.89 \mathrm{~mm})$, the difference was statistically significant $(\mathrm{p}<0.001)$. Anterior chamber depth $(\mathrm{ACD})$ was statistically deeper in the Primary Open Angle Glaucoma group $(3.05 \pm 0.51 \mathrm{~mm})$ as compared to the control group $(2.86 \pm 0.46 \mathrm{~mm}),(\mathrm{p}<0.01)$. Central corneal thickness (CCT) was thinner in the Primary Open Angle Glaucoma group (519.5 $\pm 36.25 \mathrm{um}$ ) as compared to the control group $(525.40 \pm 37.77 \mathrm{um})$ but the difference was not found to be statistically significant $(\mathrm{p}<0.19)$. K value in Primary Open Angle Glaucoma $(7.54 \pm 0.41 \mathrm{~mm})$ was higher than agematched controls $(7.58 \pm 0.33 \mathrm{~mm})$ but the difference was not statistically significant $(\mathrm{p}<0.79)$.

Conclusion: Patients with Primary Open Angle Glaucoma had longer Axial length (AL) and deeper Anterior chamber depth (ACD) as compared to normal individuals.

Key words: Biometry, Primary Open Angle Glaucoma.

$\begin{array}{ll}\text { Financial Interest : Nil } & \text { Received : 21.01.2021 } \\ \text { Conflict of Interest : Nil } & \text { Accepted : 02.05.2021 } \\ \text { Corresponding Author } & \\ \text { Dr. Nisha Manandhar } & \\ \text { Kirtipur Eye Hospital } & \\ \text { Tahalcha, Kirtipur, Nepal. } & \\ \text { E-mail: nizamanandhar@gmail.com } & \\ \text { Contact: +97719851021999 }\end{array}$

Contact: +97719851021999
Access this article online

Website: www.nepjol.info/index.php/NEPJOPH

DOI: https://doi.org/10.3126/nepjoph.v13i2.34048

Copyright $\odot 2021$ Nepal Ophthalmic Society ISSN: 2072-6805, E-ISSN: 2091-0320

This work is licensed under a Creative Commons

Attribution-NonCommercial-NoDerivatives 4.0

International License (CC BY-NC-ND). 


\section{INTRODUCTION}

Glaucoma is one of the major causes of irreversible blindness worldwide. Quigley and Broman had estimated the total burden of glaucoma to be 60.5 million worldwide in 2010 , which is expected to increase to 79.6 million by 2020 , and among these $74 \%$ will have open angle glaucoma (OAG). Asian population is expected to represent $47 \%$ of all glaucoma patients and among these, $87 \%$ will have Angle Closure Glaucoma (ACG) (Quigley et al, 2006).

According to the Nepal blindness survey of $1984,3.2 \%$ of the total blindness in Nepal was reported due to glaucoma (Brilliant et al, 1985). In a population based study done in Kathmandu Valley in 2012, the prevalence of glaucoma was found to be $1.9 \%$, among which Primary Open Angle Glaucoma (POAG) was seen in 1.24 $\%$, Primary Angle Closure Glaucoma (PACG) in $0.39 \%$ and secondary glaucoma in $0.15 \%$. Nine eyes were blind and two subjects were bilaterally blind due to glaucoma (Thapa et al, 2013).

Primary open angle glaucoma is one of the most common forms of glaucoma (Yasuyuki et al, 2006). There are many risk factors associated with POAG. High intraocular pressure (IOP) is seen in most individuals diagnosed with POAG.
Furthermore, many people with high IOP may never develop glaucomatous optic nerve damage. Other risk factors like thin central corneal thickness (CCT), old age, black race, family history of glaucoma, are associated with increased risk of POAG (Worley et al, 2011).

The main aim of our study was to compare the Axial Length (AL), Anterior Chamber Depth (ACD), Keratometry (K) and Central Corneal Thickness (CCT) between patients diagnosed with POAG and age matched controls.

\section{MATERIALS AND METHODS}

It was a hospital based cross-sectional study done at Mechi Eye Hospital. In this study we included patients diagnosed with POAG with age more than $40 \mathrm{yrs}$ and age matched controls with similar refractive error who were posted for cataract surgery. The study period was of 6 months from 1st July 2018 to 31 st Dec 2018. It included 212 patients. If both eyes of the subject were eligible only one phakic eye was selected for analysis. Ethical clearance was obtained from The Institutional ethical committee. Diagnosed cases of POAG whose diagnosis was done according to the International Society for Geographic and Epidemiological Ophthalmology (ISGEO) guidelines as shown in table 1(Foster et al, 2002) were included. 
Table 1: ISGEO Classification of Glaucoma.

The diagnosis of Glaucoma in Cross -sectional prevalence surveys

The prevalence of glaucoma would be based on three levels of evidence:

1. Diagnosis based on the presence of structural and functional evidence where there is intraocular pressure $>20 \mathrm{mmHg}$, vertical cup-to-disc ratio $>0.6$, or difference in vertical cup-to-disc ratio between 2 eyes of $>0.2$.

2. Diagnosis based solely on structural evidence where visual field testing was not satisfactorily completed.

3. Diagnosis where the optic disc cannot be assessed and visual field testing is impossible but with VA $<20 / 200$ (LogMAR 0.10) and intraocular pressure $>21 \mathrm{mmHg}$ or VA $<20 / 200$ (LogMAR 0.10) in an eye which shows evidence of glaucoma filtering surgery, or medical records were available confirming glaucomatous visual morbidity.

\section{Clinical Examination:}

Patients' demographic profiles were recorded. Visual acuity was recorded using Snellen's chart. Goldman Applanation Tonometer (Haag-Streit, Koeniz, Switzerland) was used for measurement of Intraocular Pressure. The estimation of Vertical cup-disc ratio (CDR) in the slit lamp was done with a Volk 90D after pupillary dilatation. A 3-mirror Goldman lens (HaagStreit, Koeniz Switzerland)was used for gonioscopy. AL, ACD, and $\mathrm{K}$ values were measured with an IOLMaster 500, Carl Zeiss Meditec AG, Germany master. CCT was measured using Ultrasonic Pachymetry.

Exclusion criteria:

Age of patient $<40$ years, secondary glaucoma, Primary angle closure glaucoma (PACG), pseudophakic patients, intraocular pathologies altering IOP like uveitis, past ocular surgery.

Statistics and data analysis:

Data entry was done in SPSS version 11. Mann-
Whitney $U$ test was used for the statistical analysis to find correlation between dependent variables between two groups. Statistical tools used were Mean, Range, Percentage and Standard deviation.The correlation was considered significant if $p$ value was less than 0.05 .

\section{RESULTS}

The total number of patients with POAG was 137 (137 eyes) and that of age matched control was 75 ( 75 eyes). Mean age of patients with POAG was $55.25 \pm 10.16$ years, ranging from 40 to 82 years. Mean age of the control group was $60.96 \pm 10.91$ years, ranging from 35 to 90 years. In the POAG group the total number of males was $90(65.2 \%)$ and females was $47(34.3 \%)$ whereas in the control group the total number of male was $33(44 \%)$ and female was 42 (56\%).

As shown in Table 2, in the POAG group the AL ranged from $(20.31 \mathrm{~mm}-32.66 \mathrm{~mm})$ and the mean AL was $23.16 \pm 1.19 \mathrm{~mm}$. In the control group the AL ranged from $(20.02 \mathrm{~mm}-$ 
Table 2: Showing Mean Axial Length, Central Corneal Thickness, Corneal curvature and Anterior Chamber Depth in Control eyes and POAG eyes.

\begin{tabular}{|l|c|c|c|}
\hline \multicolumn{1}{|c|}{ Variable } & Control eyes $(\mathbf{n = 7 5 )}$ & POAG eyes $(\mathbf{n = 1 3 7})$ & P value \\
\hline Axial length $(\mathrm{mm})$ & $22.69 \pm 0.89 \mathrm{~mm}$ & $23.16 \pm 1.19 \mathrm{~mm}$ & $<0.001$ \\
\hline Central corneal thickness $(\mathrm{mm})$ & $525.4 \pm 37.77 \mathrm{um}$ & $519.5 \pm 36.25 \mathrm{um}$ & 0.19 \\
\hline Corneal curvature $(\mathrm{mm})$ & $7.58 \pm 0.33 \mathrm{~mm}$ & $7.54 \pm 0.41 \mathrm{~mm}$ & 0.79 \\
\hline Anterior chamber depth $(\mathrm{mm})$ & $2.86 \pm 0.46 \mathrm{~mm}$ & $3.05 \pm 0.51 \mathrm{~mm}$ & $<0.01$ \\
\hline
\end{tabular}

$24.76 \mathrm{~mm}$ ) and mean AL was $22.69 \pm 0.89 \mathrm{~mm}$. Axial length was longer in the POAG group than in the control group and was found to be statistically significant $(\mathrm{p}<0.001)$.

CCT in the POAG group ranged from $(426 \mathrm{~mm}$ $-664 \mathrm{~mm})$ and in the control group it ranged from $(382 \mathrm{~mm}-602 \mathrm{~mm})$. CCT was thinner in POAG group $519.5 \pm 36.25 \mathrm{~mm}$ as compared to control group $525.4 \pm 37.77 \mathrm{~mm}$. The difference was not statistically significant $(\mathrm{p}=0.19)$.

Mean K value in POAG group was $7.54 \pm 0.41 \mathrm{~mm}$ and in control group was $7.58 \pm 0.33 \mathrm{~mm}$ but the difference was not statistically significant $(p=0.79)$. Mean ACD in the POAG group was $3.05 \pm 0.51 \mathrm{~mm}$ and in the control group was $2.86 \pm 0.46 \mathrm{~mm}$ and the difference was statistically significant $(\mathrm{p}<0.01)$.

\section{DISCUSSION}

$\mathrm{AL}$ is one of the risk factors for glaucoma. Patients with high axial myopia have thin sclera and lamina cribrosa which are responsible for high scleral tension(Funata et al, 1990; Jonas et al, 2004). As a result, it can cause biomechanical changes of the optic nerve head and increase the risk of glaucomatous damage of the optic nerve head (Sigal et al , 2005). In our study, the AL in POAG group was found to be significantly higher $(p<0.001)$ than age matched controls. In the study done by Oku et al (2009), POAG patients were compared with control subjects which showed that the increased axial length and increased IOP were significantly associated with POAG. Whereas when control subjects were compared with NTG patients only axial length was found to be significantly associated. In the Singapore Malay Eye Study done by Perera et al(2010), longer axial length was associated with POAG. Patients with moderate to high myopia were more likely to have POAG, the association was found to be significant after the CCT adjustment. CCT and corneal curvature were not found to be significantly associated with POAG. Another study conducted by Pai et al(2017), also showed that the increasing AL was significantly associated with POAG. In the Meiktila eye study conducted by Casson et al(2007) the AL, myopia and increasing age were significantly associated with open angle glaucoma in univariate analysis.

Thin CCT is also one of the risk factors for POAG. Thin central cornea leads to underestimation of true IOP which may result in 
late diagnosis thus resulting in greater damage of optic nerve (Ulmer et al, 2012). In our study the POAG group had thinner CCT as compared to the control group but it was not statistically significant $(p=0.19)$. In the study conducted by Ulmer et al (2012), POAG cases had lower CCT than the control cases and the CCT between POAG cases and control cases was significantly different. Within the POAG cases, the low tension subset had significantly lower mean CCT compared with the high-tension subset.Another study done by Mokbel et al (2010) showed that thin CCT was significantly correlated with neuroretinal rim area loss, optic disc area, vertical and horizontal cup to disc ratio. Thin CCT was also significantly associated with worsened mean deviation of visual field and increased use of antiglaucoma medications. In the study conducted by Papadia et al (2007), the correlation between CCT and both SD and PSD was found to be significant. Thinner cornea was significantly associated with the worst damage. Kohlhaas et al (2006) showed strong correlation between CCT and IOP obtained by Goldmann Applanation Tonometry at three IOP levels $20 \mathrm{mmHg}, 35 \mathrm{mmHg}$ and $50 \mathrm{mmHg}$, whereas the correlation between IOP and corneal curvature and IOP and axial length at all three IOP levels were not found to be significant.

Regarding the correlation between corneal curvature and POAG, very few studies have been published. Corneal curvature is also considered as one of the factors to influence the accuracy of IOP (Whitacre et al, 1993). The steeper the corneal curvature, more area of the cornea needs to be indented to produce the standard area of contact. Therefore, the IOP measurement is expected to be artifactually higher in steeper cornea and lower in flatter cornea (Harada et al, 2008).In the study done by Mark (1973), it was found that increase of $1.0 \mathrm{D}$ in curvature corresponds to an increase of $0.34 \mathrm{~mm} \mathrm{Hg}$ in the tonometric value. In our study corneal curvature was more in the POAG group as compared to the control group. The association was not found to be statistically significant. Morad et al(1988) conducted a study which showed that the corneal curvature was similar in NTG patients, POAG patients and healthy subjects. The difference between the group was not found to be statistically different. Harada et al (2008) conducted a study in which the correlation of $\mathrm{CCT}$ and corneal curvature on IOP measured by Goldmann Applanation tonometer was examined. No significant correlation was found between IOP measured by non-contact applanation tonometer and corneal curvature radius.In the study done by Gunvant et al (2004), the effect of CCT and corneal curvature on IOP was measured. The mean corneal curvature when increased by $1 \mathrm{~mm}, 1.14 \mathrm{mmHg}$ rise in IOP was seen by GAT and $2.6 \mathrm{mmHg}$ rise in IOP by pulsatile ocular blood flow tonograph. In the Tajimi Study done by Yasuyuki et al (2006), no significant correlation was found between corneal curvature and glaucoma.

In our study the ACD was deeper in POAG patients as compared to control and it was significantly associated. Also the AL was more in POAG patients. So greater the AL, greater 
should be ACD. In the study done by Maggon et al (2019), AL and ACD was measured in patients who reported for cataract surgery. It showed that as the mean AL increased, there was an increase in mean ACD also. There was a weak positive correlation of 0.13 which was statistically significant. Adewara et al (2017) conducted a study which showed that the mean ACD in the control group was higher than in the control group. The difference was not found to be statistically significant. In the glaucoma group positive correlation was found between IOP and ACD.In the Singapore Malay Eye study done by Perera et al (2010), the mean ACD was more in the control group than in the POAG group but the difference was not significantly associated.

\section{CONCLUSION}

In conclusion, patients with POAG had longer Axial length (AL) and deeper Anterior chamber depth (ACD) as compared to normal subjects and the association was statistically significant.

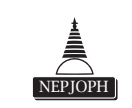

\section{REFERENCES}

Adewara BA, Adegbehingbe BO, Onakpoya OH, Ihemedu CG (2017). Relationship between intraocular pressure, anterior chamber depth and lens thickness in primary open-angle glaucoma patients. Int Ophthalmol;38(2):541-7. doi:10.1007/s10792-017-0488-4; PMid:28289948

Brilliant LB, Pokhrel RP, Grasset NC, Lepkowski JM, Kolstad A, Hawks W, et al. (1985). Epidemiology of blindness in Nepal. Bulletin of the World Health Organization;63(2):375-86.

Casson RJ, Gupta A, Newland HS, Mcgovern S, Muecke J, Selva D et al. (2007). Risk factors for primary open-angle glaucoma in a Burmese population :The Meiktila Eye Study. Clinical and Experimental Ophthalmology;35:739-44. doi:10.1111/j.1442-9071.2007.01619.x; PMid:17997778

Foster PJ, Buhrmann R, Quigley HA, Johnson GJ (2002).The definition and classification of glaucoma in prevalence surveys. Br J Ophthalmol;86(2):238-42. doi: 10.1136/bjo.86.2.238; PMid:1181535

Funata M, Tokoro T (1990). Scleral change in experimentally myopic monkeys. Graefe's Archive Ophthalmology;228:174-9. doi: 10.1007/BF00935729

Gunvant P, Baskaran M, Vijaya L, Joseph IS, Watkins RJ, Nallapothula M, et al. (2004). Effect of corneal parameters on measurements using the pulsatile ocular blood flow tonograph and Goldmann applanation tonometer. Br $\mathrm{J}$ Ophthalmol;88(4):518-22. doi:10.1136/bjo.2003.019331; PMid:15031169

Harada Y, Hirose N, Kubota T, Tawara A (2008). The Influence of Central Corneal Thickness and Corneal Curvature Radius on The Intraocular Pressure as Measured By Different Tonometers : Non contact and Goldmann Applanation Tonometer. J Glaucoma;17(8):619-25. doi: 10.1097/IJG.0b013e3181634f0f; PMid:19092456

Jonas JB, Berenshtein E, Holbach L (2004). Lamina cribrosa thickness and spatial relationships between intraocular space and cerebrospinal fluid space in highly myopic eyes. Investig Ophthalmol Vis Sci;45(8):2660-5. doi:10.1167/ iovs.03-1363; PMid:15277489 
Kohlhaas M, Boehm AG, Spoerl E, Pürsten A, Grein HJ, Pillunat LE (2006). Effect of Central Corneal Thickness, Corneal Curvature, and Axial Length on Applanation Tonometry. Arch Ophthalmol;124(4):471-6. doi: 10.1001/ archopht.124.4.471; PMid:16606871

Maggon R, Singh SK, Jha M, Mishra A, Gupta S, Sharma V (2019). Correlation between ocular axial length and anterior chamber depth and a differential analysis in same - sized eyes. Kerala J Ophthalmol;31(1):28-2. doi: 10.4103/ kjo.kjo_93_18

Mark HH (1973). Corneal Curvature in Applanation Tonometry. Am J Ophthalmol;76(2): 223-4. doi:10.1016/00029394(73)90164-5

Mokbel TH, Ghanem AA (2010). Correlation of central corneal thickness and optic nerve head topography in patients with primary open-angle glaucoma. Oman J Ophthalmol;3(2):75-80. doi:10.4103/0974-620X.64231; PMid:21217900

Morad Y, Sharon E, Hefetz L, Nemet P (1988). Cornea1 Thickness and Curvature in Normal-tension Glaucoma. Am J Ophthalmol;125(2):164-8. doi: 10.1016/S0002-9394(99)80086-5

Oku Y, Oku H, Park M, Hayashi K, Takahashi H, Shouji T, Chihara E (2009). Long axial length as risk factor for normal tension glaucoma. Graefe's Arch Clin Exp Ophthalmol;247(6):781-7. doi:10.1007/s00417-009-1045-2; PMid:19194720

Pai V, Thota RS (2017). Ocular Biometry in Patients with Primary Open Angle Glaucoma (POAG). Journal of Eye Diseases and Disorders;2(1):2-4. doi: 10.35248/2684-1622.17.2.108

Papadia M, Sofianos C, Lester M, Bricola G, Mete M, Traverso CE (2007). Corneal thickness and visual field damage in glaucoma patients. Eye;21:943-7.doi: 10.1038/sj.eye.6702350; PMid:16645628

Perera SA,Wong TY, Tay WT, Foster PJ, Saw SM, Aung T (2010). Refractive Error, Axial Dimensions, and Primary Open-Angle Glaucoma:The Singapore Malay Eye Study. ArchOphthalmol;128(7):900-5. doi: 10.1001/ archophthalmol.2010.125; PMid:20625053

Quigley HA, Broman AT (2006). Number of people with glaucoma worldwide in 2010 and 2020. Br J Ophthalmol;90(5):262-7. doi: 10.1136/bjo.80.5.389; PMid:8695555

Sigal IA, Flanagan JG, Ethier CR (2005).Factors influencing optic nerve head biomechanics. Investig Ophthalmol Vis Sci;46(11):4189-99. doi:10.1167/iovs.05-0541; PMid:16249498

Thapa SS, Paudyal I, Khanal S, van Rens G (2013). Results of the Bhaktapur Glaucoma Study, Nepal. Nepal J Ophthalmol;5(9):81-93. doi: 10.3126/nepjoph.v5i1.7832; PMid:23584652

Ulmer M, Li J, Yaspan BL, Ozel AB, Richards JE, Moroi SE, et al. (2012). Genome-Wide Analysis of Central Corneal Thickness in Primary Open-Angle Glaucoma Cases in the NEIGHBOR and GLAUGEN Consorti. Invest Ophthalmol Vis Sci;53(8):4468-74. doi: 10.1167/iovs.12-9784; PMid:22661486

Whitacre MM, R Stein (1993). Sources of Error With Use of Goldmann-type Tonometers. SurvOphthalmol;38(1):1-30. doi: 10.1016/0039-6257(93)90053-A

Worley A, Grimmer-Somers K (2011). Risk factors for glaucoma: what do they really mean. Aust J Prim Health;17:233-9. doi: 10.1071/PY10042; PMid:21896259

Yasuyuki S, Aiko I, Makoto A, Tetsuya Y, Haruki A, Shiroaki S, Yasuaki K, Hiromu MK, Hiroyuki S, Goji T, Yoichi I, Yoshiaki K (2006). Risk Factors for Open-Angle Glaucoma in a Japanese Population The Tajimi Study. Ophthalmology;113(9):1613-7. doi: 10.1016/j.ophtha.2006.03.059; PMid:16828504 